\title{
Particip(ação) de mulheres na política social
}

Verônica Werle*

SIMILI, Ivana Guilherme. Mulher e política: a trajetória da primeira-dama Darcy Vargas (1930-1945). São Paulo: UNESP, 2008.

Palavras-chave: política social; mulheres; história.

Keywords: social policy; women; history.

O livro Mulher e política: a trajetória da primeira-dama Darcy Vargas (1930-1945) resultante da tese de doutoramento de Ivana Simili mostra, através do percurso trilhado pela protagonista do livro, a relação e a participação da mulher na política. A autora inova ao conferir importância política para as ações femininas e na percepção da mulher como agente e sujeito de sua própria história, fatos muitas vezes negligenciados pela história oficial.

Para além das representações sociais de feminilidade relativas a maternidade e ao casamento, marcadas intensamente nas pessoas e na sociedade do início do século XX, Ivana aponta e discorre sobre as especificidades da atuação de Darcy na política social devido ao fato de estar casada com um homem público, o ex presidente Getúlio Vargas.

A cronologia da narrativa com conteúdo biográfico acompanha a história política do Brasil, em especial o período de presidência de Getúlio Vargas entre 1930 e 1945, recriando o contexto dos acontecimentos utilizando-se de livros, diários, acervos de notícias, imagens e memórias relativas ao casal.

No decorrer do texto observa-se a opção da autora em trabalhar com a categoria mulher, ao invés de usar a categoria mulheres, no plural, ou então a dimensão de gênero. Apesar de respeitar a posição da autora e sua ênfase numa determinada trajetória, e por isso a opção pelo termo mulher, penso que, em alguns momentos, as representações

\footnotetext{
* Mestranda do Programa de Pós-Graduação em Educação Física da Universidade Federal de Santa Catarina. Bolsista CNPq.
} 
observadas em Darcy podem ser ampliadas para outras mulheres que participaram e participam da política, respeitando a pluralidade das mulheres e suas particularidades. Mesmo considerando o foco dado a personagem feminina, há uma carência no que tange a condição, ou condições, masculinas da época.

O livro divide-se em três capítulos nomeados: Casamento, maternidade e política; A fundação Darcy Vargas e a infância e A primeira-dama, a legião Brasileira de Assistência e as mulheres na Segunda Guerra Mundial.

O primeiro capítulo percorre o caminho entre o casamento e a tomada do Governo Federal por Getúlio Vargas em 1930, compreendendo o periodo antecedente, referente ao governo do estado do Rio Grande do Sul. Inicialmente mostra o casal cumprindo com o modelo de feminilidade e masculinidade desenhado e desejado na época pelo ideáis liberais e positivistas, no qual os espaços públicos e a atuação profissional e política estavam destinados aos homens assim como os espaços privados relacionados a família e a maternidade estavam destinados às mulheres. A autora enfatiza a educação de caráter unicamente elementar para as mulheres, voltadas para os afazeres doméstico e para bem representar o marido socialmente.

Apesar dessas representações serem comuns às mulheres e homens da época, a especificidade de Darcy ser esposa de um homem público trouxe mudanças no cotidiano familiar, entre elas a necessidade de se habituar com recepções e festas. Neste momento Ivana reflete sobre a participação feminina no espaço público ser condicionada ao intermédio homem.

O livro mostra como de alguma forma, Darcy participava dos jogos políticos de Getúlio, abrindo a porta para os revolucionários, preservando as crianças, ajudando a decifrar telegramas, num conjunto articulado de "ajudas" em prol dos interesses do homem público. No entanto, Ivana mostra com propriedade que a participação de Darcy vai muito além destas ajudas. Durante a revolução de 1930, planejada por Getúlio para tomada do Governo Federal, a primeira-dama articulava com as mulheres dos revolucionários formas de ajudar as famílias, já que os maridos tinham largado tudo em nome da causa revolucionária. Para esta finalidade Darcy cria a Legião da Caridade. Apesar de dar visibilidade e importância, exemplificando a participação ativa de Darcy na política, cabe analisar que a autora justifica tal participação pela subordinação da esposa pelo marido e 
suas vontades, sendo necessário refletir a partir de um olhar pelo qual as atividades pudessem estar pautadas também em vontades e interesses próprios.

Assim, conforme o entendimento da autora, a assistência filantrópica promovida pela Legião da Caridade foi o meio que Darcy encontrou para ajudar a luta política do marido, e cujo caráter era de atendimento emergencial às famílias dos revolucionários. De qualquer forma esta também era uma maneira das mulheres saírem da restrição dos lares e participarem da luta política. A atuação feminina no campo social era permitida dentro da política dos homens por remeter às características maternais e benevolentes "naturalmente" femininas, bem como ao fato de a questão social não ser legitimada pelo poder dominante do Estado, não sendo considerada uma "questão propriamente política".

Mesmo com a tomada de Vargas ao poder Federal, e a mudança da família para o Rio de Janeiro, Darcy continua sua atuação "político-filantrópica-assistencial" (p.45) criando a Fundação Darcy Vargas e se tornando presidente da Legião Brasileira de Assistência.

As três fases do governo Vargas, incluindo o governo provisório de 1930 a 1934, o governo constitucional de 1934 a 1937 e o Estado Novo entre 1937 a 1945, marcam um período de contradição que, entre outros, possibilitou a inserção da mulher no meio público, devido a necessidade de mão de obra na industrialização mas também foi tomado pelos discursos moralistas. Estes comportamentos femininos na verdade "eram vistos como uma ameaça a ordem instituída, sob o signo dos interesses masculinos que temiam a perda de seu predomínio nas relações de poder entre os gêneros"( p.86), além de irem contra o projeto nacional instituído pelo Estado Novo, onde o papel de educar os filhos da nação, destinado às mulheres, era fundamental. Na prática as contradições deste governo são observadas pela aprovação do Códico Eleitoral, que deu direito ao voto secreto e ao voto das mulheres e, em sua fase ditatorial, exerceu o controle e a censura, impossibilitando os movimentos feministas.

Apesar de todo poder atribuído a Vargas, devido as representações de seus papeis como pai, esposo e presidente, dois epísódios trazidos pelo livro mostram a necessidade da figura da mulher como esposa para os interesses políticos. O primeiro, trata-se do casamento religioso aceito por Vargas a pedido da esposa e o segundo, o fato de Darcy permanecer com o marido, porém com separação de corpos, após saber de suas relações extra conjugais. Os exemplos demonstram como as relações de poder circulam, não são fixas 
em um dominante, ambos cedem em determinado momento considerando os aspectos políticos, nos quais estão atrelados o comportamento exemplar esperado de um presidente. "A existência das esposas e, principalmente, a exposição delas pelos governantes dão a ver o que eles são no privado: maridos e pais de família, fornecendo, assim, as bases para a criação de representações públicas como bons maridos e pais" (p.59).

Com a entrada do país na Segunda Guerra Mundial, Darcy cria a Legião Brasileira de Assistência, com a mesma intenção que criara a Legião da Caridade "amparar os soldados e seus familiares" da qual só se afastara devido a morte do filho caçula em 1943.

O segundo capítulo trata mais especificamente da participação de Darcy e das mulheres nas políticas sociais, tendo como base as entidades criadas pela primeira-dama: 1938-Fundação Darcy Vargas, que defendia questões sociais relativas a infância; 1940- Casa do Pequeno Jornaleiro, destinada a prevenção da delinquência dos pequenos vendedores de jornais e 1942 - A Legião Brasileira da Assistência que prestava assistencia aos soldados da Segunda Guerra e seus familiares.

O aumento das contradições sociais decorrentes da implantação do sistema capitalista promoveu mudanças no atendimento as questões sociais. A pobreza, a marginalidade e os demais problemas sociais que antes eram tratados pela repressão policial e pela caridade religiosa, passam a ser considerados questão de estado através de políticas sociais. Estas mantidas pelo estado e por empresários, mas responsabilidade da sociedade, em especial do voluntariado feminino das entidades filantrópicas, destacando-se as criadas por Darcy.

Ivana contribui, apoiada em outros autores, sobre como a política social da época estava relacionada à noção de cidadania e esta ao reconhecimento profissional. Aqueles cuja profissão era reconhecida eram considerados cidadãos e, portanto, possuidores do direito às políticas sociais. Os demais trabalhadores eram considerados pré-cidadãos, restando-Ihes o "favor" do assistencialismo. Hoje, pode-se dizer que a questão só constituiu a forma de um direito universal, apesar de ainda não ser consolidada na prática, a partir da promulgação da Constituição Federal de 1988.

Outras mulheres e feministas que atuaram no campo político e assistencial também são destacadas no livro e, apesar de enfoques diferentes, tinham como objetivos maiores a melhoria da situação da mulher e das crianças, muitas vezes através de medidas 
formativas/educacionais. Mesmo com as ações de Darcy caminhando a partir dos interesses do marido, a autora destaca como a prática dessas mulheres era baseada no papel de mulheres e mães, portanto, de personagens que lutavam por questões que Ihes diziam respeito, como a maternidade e a infância.

Outra reflexão valiosa refere-se a forma como surgiram as políticas sociais. Apesar de nascerem das necessidades e reivindicações do povo e dos trabalhadores, as políticas sociais também conduziram para os interesses político (de expansão capitalista, através da reprodução de força de trabalho) e ideológico (num projeto de país forte e unido). A Casa do Pequeno Jornaleiro ilustra bem esta política, pois por trás da preocupação em melhorar as condições de vida das crianças e jovens destinava-se ao preparo de mão-de-obra barata e dócil para o trabalho.

Como já foi explicado, a participação da mulher nesta política deveu-se ao entendimento das suas competências de cuidar e proteger, tidas como naturais. Em relação a Darcy, a autora novamente destaca que, para além das competências femininas, sua atuação estava intimamente ligada aos interesses políticos do marido. Apesar de estarem sob o controle do Estado e dos empresários que mantinham as entidades, as mulheres foram responsáveis e determinantes para a consolidação destas políticas. O que mostra claramente também a transferência de responsabilidade social do Estado para as entidades filantrópicas, protagonizadas por mulheres.

O terceiro capítulo retoma as reflexões já organizadas sobre as características e surgimento das políticas sociais, enfocando a participação da mulher na 2a Guerra, principalmente através da Legião Brasileira da Assistência (LBA).

A LBA, entidade criada e conduzida também pela primeira-dama para prestar assistência aos soldados da Segunda Guerra Mundial e seus familiares, marca o surgimento das políticas públicas no Brasil, sendo a primeira instituição pública assistencial bem como, marca a atuação feminina neste setor, sendo que Darcy Vargas assume o primeiro cargo público ocupado por uma mulher na esfera pública estatal do país.

Através da entidade, Darcy mobilizou um grande número de mulheres voluntárias em nome da união do país frente a situação de Guerra, numa ação paralela ao presidente que mobilizava os homens para combate, ações que serviam para promover, ao mesmo tempo, o sentimento nacionalista e o marketing político. As atividades exercidas pelas voluntárias, 
além dos cargos de chefia destinados às mulheres de elite, eram a costura, o tricot e os cursos que envolviam conhecimentos sobre defesa passiva, alimentação, primeiros socorros e educação popular. A atuação feminina na Segunda Guerra mostra como as atribuições da mulher para com a família, deveriam ser ampliadas para toda a nação confirmando-se o objetivo de construir um país forte e unido, com brasileiros saudáveis e trabalhadores.

Os cursos e as demais atividades da LBA oportunizaram o acesso das mulheres a novos conhecimentos e a iniciação às profissões de enfermeiras, nutricionistas e assistentes sociais. No entanto, por outro lado, reforçava o papel social da mulher e permitia a exploração dos sentimentos e habilidades femininas em nome do poder político.

Através da trajetória de Darcy Vargas, o livro contribui para a compreensão do surgimento das políticas sociais no Brasil, mostrando a participação hegemônica da mulher neste processo que, apesar de justificada e aceita pela suposta natureza materna, oportunizou a abertura dos espaços públicos e a sua profissionalização.

$\mathrm{Na}$ trajetória da primeira-dama são destacados os aspectos que tangem as peculiaridades do dever ser mulher, na condição imposta de esposa de um homem público e na sua participação, aparentemente secundária, porém fundamental no projeto político do marido. Neste sentido, quando a autora destaca que para além da sua importância na política do marido, Darcy exerce sua própria atuação e seu pioneirismo frente ao projeto assistencial nacional, fica a impressão de que o livro carece refletir sobre a individualidade da protagonista.

Recebido em 10/12/2009.

Aprovado para publicação em 15/12/2009. 